\title{
Defining Benign/Burnt-Out MS and Discontinuing Disease-Modifying Therapies
}

Derek McFaul, DO, Nektar N. Hakopian, PharmD, Jessica B. Smith, MPH, Allen Scott Nielsen, MD, and Annette Langer-Gould, MD, PhD

Neurol Neuroimmunol Neuroinflamm 2021;8:e960. doi:10.1212/NXI.0000000000000960

\section{Abstract}

\section{Objective}

To determine whether MS disease-modifying therapies (DMTs) can be safely discontinued in patients aged 50 years or older with suspected benign/burnt-out MS and to define criteria to identify such patients.

\section{Methods}

We conducted a retrospective cohort study of 136 patients with suspected benign/burnt-out MS who discontinued DMTs from the electronic health record (EHR) at Kaiser Permanente Southern California.

\section{Results}

The majority discontinued an injectable DMT $(n=131,96 \%)$. At the time of DMT discontinuation, mean and SD for age was 60.6 (6.2) years, disease duration 19.5 (10.7) years, and time since last relapse 11.0 (7.2) years. After a mean duration of follow-up of 5.0 years postDMT discontinuation, 5 (3.7\%) patients had a relapse, 2 (1.5\%) had mild residual deficits, and $3(2.2 \%)$ had asymptomatic MRI disease activity. Patients with MS disease activity following DMT discontinuation were younger (median $=53.6$ years) than those who remained disease activity free. Fifty patients $(36.8 \%)$ had only 1 lifetime relapse, of whom 1 relapsed post-DMT discontinuation. Sixty (56.6\%) of 106 patients with spinal cord MRIs before discontinuation showed demyelinating lesions.

\section{Conclusions}

DMT discontinuation in older patients with suspected benign/burnt-out MS appears safe. Our findings suggest that MRI evidence of spinal cord involvement does not preclude the possibility of benign/burnt-out MS, and for those with 2 or more lifetime relapses, a benign/burn-out classification is best reserved for those aged 55 years and older. Future studies to determine whether DMT discontinuation is safe at a younger age in patients with a single lifetime relapse are needed.

\section{Classification of Evidence}

The study provides Class IV evidence that DMTs can be safely discontinued in older patients with suspected benign/burnt-out MS.
Correspondence

Dr. Langer-Gould

Annette.M.Langer-Gould@kp.org
MORE ONLINE

$\rightarrow$ Class of Evidence

Criteria for rating therapeutic and diagnostic studies

NPub.org/coe 


\section{Glossary}

CIS = clinically isolated syndrome; DMT = disease-modifying therapy; EDSS = Expanded Disability Status Scale; EHR = electronic health record; IQR = interquartile range; KPSC = Kaiser Permanente Southern California; NNT = number needed to treat; PPMS = primary progressive MS; RRMS = relapsing-remitting MS; SPMS = secondary progressive MS.

The effect of immunosenescence ${ }^{1}$ in MS is characterized by dissipation of relapses and inflammatory MRI activity in the elderly, at which point patients either transition to secondary progressive MS (SPMS) or not. Population-based studies indicate that up to $40 \%$ of patients with relapsing-remitting MS (RRMS) do not transition to SPMS and never develop clinically important disability. ${ }^{2,3}$ There is, however, no consensus on precisely which term should be used to denote such elderly persons with MS who do not transition to SPMS.

The term benign MS is controversial, ${ }^{4,5}$ as many studies define it as the absence of physical but not cognitive disability. ${ }^{6}$ Benign MS also does not capture those patients who reach immunosenescence and never transition to SPMS but have significant disability acquired from old relapses. Thus, we prefer the term benign/burnt-out MS to capture the full spectrum of MS-related disability that can occur in elderly patients who never transition to SPMS.

Disease-modifying therapies (DMTs) have demonstrated short-term benefit in patients with active RRMS by reducing the frequency and severity of relapses and formation of new lesions on brain MRIs. ${ }^{7}$ But the evidence supporting continuing DMTs in patients with long-standing and inactive MS is weak to nonexistent. ${ }^{8}$

Several observational studies suggest that discontinuing DMTs, particularly in older patients, ${ }^{9}$ does not lead to inflammatory disease activity in excess of those who remain on DMTs. ${ }^{9-11}$ These results are reassuring but do not specifically address patients with suspected benign/burnt-out MS, as the studies included young patients ${ }^{10,11}$ in whom a benign disease course cannot be accurately predicted and/or patients with progressive $\mathrm{MS}^{9,11}$ in whom randomized controlled trials of most DMTs have failed to demonstrate benefit. ${ }^{12}$

The purpose of this study was to assess the safety of discontinuing DMTs in patients with suspected benign/burnt-out MS and develop a consensus case definition based on the results.

\section{Methods}

\section{Overview}

We developed guidance for when continuing or discontinuing DMTs was in equipoise in 2013 as requested by our general neurologists. They, like others, were increasingly encountering patients who do not want to take DMTs in perpetuum for a variety of reasons including but not limited to financial toxicity. ${ }^{8,9}$ This guidance (figure e-1, links.lww.com/NXI/
A408) incorporated concepts of benign/burnt-out MS, prevalent MS cases with minimal disease activity, and what was called clinically isolated syndrome (CIS) and now MS. ${ }^{13}$ To specifically define benign/burnt-out MS and the safety of DMT discontinuation, we conducted a retrospective cohort study of all patients with relapsing, nonprogressive MS aged 50 years or older who discontinued their MS DMT from January 1,2012, to December 31, 2016, while receiving care in Kaiser Permanente Southern California (KPSC).

The primary study outcome was incomplete recovery from MS relapse following DMT discontinuation. This was chosen because it is clinically meaningful, all MS DMTs have been shown to reduce the risk of relapses, and most DMTs also reduce the risk of incomplete recovery from relapses. ${ }^{7}$ Secondary outcomes included conversion to SPMS and a combined outcome of any inflammatory disease activity, defined as any MS relapse (regardless of degree of recovery) and/or any MS-related MRI disease activity following DMT discontinuation. Outcomes and covariates were abstracted from the complete electronic health records (EHRs) through October 1, 2019. These findings were used to develop a consensus definition of benign/burnt-out MS and additional guidance for patients with nonprogressive MS with only a single lifetime attack. The study is rated Class IV because of the absence of a control group of patients with suspected benign/burnt-out MS who were continued on DMT.

\section{Process of Defining Benign/Burnt-Out MS}

Our definition of benign/burnt-out MS is intended to capture elderly persons with RRMS in whom discontinuing DMTs is not harmful. This requires that immunosenescence is strongly suspected, and the person has not transitioned and is at a low risk of transitioning to SPMS. To explore how immunosenescence should be defined, we examined age, time since last relapse, and time since last active MRI. Additional variables to explore risk of transitioning to SPMS were physical disability, spinal cord lesions on MRI, ${ }^{14-16}$ and whether patients met the Poser diagnostic criteria ${ }^{17}$ for definite MS because the vast majority of the prognostic literature relies on this case definition. ${ }^{18}$

Others have used the term burnt-out MS to also capture those patients with SPMS or primary progressive MS (PPMS) who have stopped progressing. ${ }^{19}$ We decided not to include these patients and prefer the term plateaued in these situations because we are not sure whether these SPMS or PPMS patients' disability level will start progressing again at a later date.

\section{Setting}

KPSC is a large prepaid health care organization that provides comprehensive health care services to over 4.6 million 
members in Southern California. The membership of KPSC is representative of the general Southern California population. ${ }^{20}$ KPSC uses an integrated EHR system, which includes all inpatient and outpatient encounters, laboratory and imaging tests, diagnoses and medications, and demographic and behavioral characteristics.

\section{Study Population}

We searched electronic databases to identify KPSC members with last dispensed date of an MS DMT between January 1, 2012, and December 31, 2016, and reviewed the EHR to confirm that the following inclusion criteria were met: (1) confirmed MS diagnosis, 2017 criteria $^{13}$; (2) discontinuation of any MS DMT between January 1, 2012, and December 31, 2016 , for at least 3 months; (3) $\geq 50$ years of age at DMT discontinuation; and (4) suspected benign/burnt-out MS at the time of discontinuation.

To identify patients with suspected benign/burnt-out MS at DMT discontinuation, we required the absence of progressive MS or active RRMS. Progressive MS was defined as documentation of progressively worsening neurologic deficits independent of relapses for at least 1 year at any time in the disease course. To account for potential discrepancies between documented subjective complaints (e.g., fatiguing leg weakness), the neurologist's physical examination findings (e.g., progressively worsening spasticity and ataxia), and/or the MS subtype documented by the neurologist (RRMS in this example), we a priori decided to rely on the documented physical examinations (in this case the patient would be classified as SPMS). Active RRMS was defined as patients with a relapse or MRI disease activity within 1 year before DMT discontinuation. Relapses were defined as the occurrence, reappearance, or worsening of symptoms of neurologic dysfunction lasting for 48 hours or more (e-Methods, links.lww.com/NXI/A409).

Exclusion criteria were (1) misdiagnosis or diagnostic uncertainty $(\mathrm{n}=17)$; (2) continued treatment with the same or another DMT ( $\mathrm{n}=32)$; (3) age <50 years at the time of DMT discontinuation $(\mathrm{n}=2)$; (4) progressive disease course at the time of DMT discontinuation $(\mathrm{n}=273)$; (5) active relapsingremitting MS at the time of discontinuation $(n=4)$; (6) discontinuation due to initiation of chemotherapy for cancer ( $\mathrm{n}=$ 6); or (7) insufficient documentation to confirm diagnosis and/ or subtype $(\mathrm{n}=5)$.

\section{Data Collection}

Data were extracted by manually reviewing the EHR through the end of the study period (e-Methods, links.lww.com/NXI/ A409). MS-related disability was obtained from neurologists' notes and other potentially MS-related visits (e.g., ophthalmology, physical therapy, urology, and psychiatry) as previously described. ${ }^{21}$ Briefly, patients were classified as no disability (normal/near-normal examinations), some disability but fully ambulatory, some ambulatory impairment but no assist device and cane, walker, or wheelchair dependent. MRI scans and radiology reports were reviewed by a neurologist
(D.M.) to identify new or enlarging T2 lesions, diffusionrestricting lesions, or gadolinium contrast-enhancing lesions and those scans obtained after DMT discontinuation were adjudicated by an MS specialist (A.L.-G.) to determine whether the new or enlarging lesions were consistent with demyelinating disease. ${ }^{22}$

\section{Statistical Analyses}

We were unable to conduct multivariable analyses because too few patients developed the primary outcome (incomplete recovery from MS relapse following DMT discontinuation, $\mathrm{n}$ $=2$ ) or other outcomes (SPMS, $\mathrm{n}=1$, any inflammatory disease activity, $\mathrm{n}=8$ ).

The mean values and SDs of normally distributed variables were compared using 2-sample $t$ tests; for variables with non-normal distributions, the Wilcoxon rank-sum test; and for binary or categorical variables, $\chi^{2}$ with the Fisher exact test. Statistical significance was set at $p=0.05$. No adjustment for multiple comparisons was made. All statistical analyses were performed using SAS version 9.4 (SAS Institute Inc., Cary, NC).

\section{Standard Protocol Approvals, Registrations, and Patient Consents}

The study protocol was approved by the KPSC Institutional Review Board (\#5707).

\section{Data Availability}

Due to KPSC's Institutional Review Board, data would be available on reasonable request.

\section{Results}

We identified 136 patients who were aged 50 years or older and had suspected benign/burnt-out MS at the time of stopping their DMTs. DMT discontinuation was primarily initiated by the patient $(n=121,89.0 \%)$, of whom $47(34.6 \%)$ discussed it with their physician before stopping (table 1). The main reasons recorded were side effects and injection fatigue. After a median follow-up time of 5.0 years (interquartile range $[\mathrm{IQR}]=4.1-5.8$ years $), 8$ patients experienced inflammatory disease activity: $3(2.2 \%)$ experienced a relapse with MRI disease activity, 2 (1.5\%) had a relapse without MRI disease activity, and another $3(2.2 \%)$ had asymptomatic MRI disease activity. Among those experiencing a relapse and/or MRI disease activity, the median time to event was 2.7 years $(\mathrm{IQR}=2.1-3.9$ years $)$ (figure 1$)$.

Table 1 shows the demographic, clinical, and MRI characteristics at the time of DMT discontinuation stratified by outcomes. The patients' median age was 60.7 years, disease duration 17.0 years, and last experienced an MS relapse 10.2 years ago. The majority were females, were stopping an interferon- $\beta$ or glatiramer acetate (GLAT) product, and had no functional limitations from MS (83.8\%, $\mathrm{n}=114$; Expanded Disability Status Scale [EDSS] or equivalent $\leq 2.5$ ) at the time 
Table 1 Characteristics at Discontinuation of MS DMT Stratified by Outcome

\begin{tabular}{|c|c|c|c|c|}
\hline & $\begin{array}{l}\text { Relapse or MRI } \\
\text { activity post-DMT }(n=8)\end{array}$ & $\begin{array}{l}\text { Relapse and MRI } \\
\text { activity-free post-DMT }(n=128)\end{array}$ & Total $(n=136)$ & $p$ Value \\
\hline Age, y, median (IQR) & $53.6(52.2-61.3)$ & $61.0(55.9-65.4)$ & $60.7(55.2-65.2)$ & 0.0274 \\
\hline Sex, $n$ (\% female) & $7(87.5)$ & $113(88.3)$ & $120(88.2)$ & 1.00 \\
\hline Race/ethnicity, n (\%) & & & & 0.3477 \\
\hline White, non-Hispanic & $6(75.0)$ & $104(81.3)$ & $110(80.9)$ & \\
\hline Hispanic & $0(0)$ & $11(8.6)$ & $11(8.1)$ & \\
\hline Black & $2(25.0)$ & $12(9.4)$ & $14(10.3)$ & \\
\hline Asian & $0(0)$ & $1(0.8)$ & $1(0.7)$ & \\
\hline Disease duration, $y$, median (IQR) & $17.8(12.5-18.9)$ & $16.8(11.9-24.9)$ & $17.0(11.9-24.6)$ & 0.6471 \\
\hline Single lifetime relapse, $\mathbf{n}(\%)$ & $2(25.0)$ & $48(37.5)$ & $50(36.8)$ & 0.7099 \\
\hline Time since last relapse, $y$, median (IQR) & $5.8(3.6-9.2)$ & $10.4(6.0-15.3)$ & $10.2(5.7-15.2)$ & 0.0765 \\
\hline Ever active MRI, n (\%) & $4(50.0)$ & $48(37.5)$ & $52(38.2)$ & $0.7115^{a}$ \\
\hline $\begin{array}{l}\text { Time since last active MRI, y, } \\
\text { median (IQR) }\end{array}$ & $7.2(4.2-9.7)$ & $5.4(2.6-7.0)$ & $5.4(2.8-7.2)$ & 0.3148 \\
\hline Ever spinal cord lesion, $\mathbf{n}(\%)$ & & & & $0.4612^{\mathrm{b}}$ \\
\hline Yes & $6(75.0)$ & $54(42.2)$ & $60(44.1)$ & \\
\hline No & $2(25.0)$ & $44(34.4)$ & $46(33.8)$ & \\
\hline Missing & $0(0)$ & $30(23.4)$ & $30(22.1)$ & \\
\hline Relapse or MRI activity in past $3 \mathrm{y}, \mathrm{n}(\%)$ & $1(12.5)$ & $22(17.2)$ & $23(16.9)$ & 1.00 \\
\hline Relapse or MRI activity in past $5 \mathrm{y}, \mathrm{n}(\%)$ & $3(37.5)$ & $40(31.3)$ & $43(31.6)$ & 0.7075 \\
\hline MS-related disability, n (\%) & & & & 0.4689 \\
\hline No disability & $6(75.0)$ & $108(84.4)$ & $114(83.8)$ & \\
\hline Some disability but fully ambulatory & $2(25.0)$ & $15(11.7)$ & $17(12.5)$ & \\
\hline Some ambulatory impairment & $0(0)$ & $1(0.8)$ & $1(0.7)$ & \\
\hline $\begin{array}{l}\text { Cane, walker, or } \\
\text { wheelchair dependent }\end{array}$ & $0(0)$ & $4(3.1)$ & $4(2.9)$ & \\
\hline Last DMT used, $\mathbf{n}(\%)$ & & & & 0.7939 \\
\hline Interferon- $\beta$ & $5(62.5)$ & $63(49.2)$ & $68(50.0)$ & \\
\hline Glatiramer acetate & $3(37.5)$ & $60(46.9)$ & $63(46.3)$ & \\
\hline Fingolimod & $0(0)$ & $2(1.6)$ & $2(1.5)$ & \\
\hline Dimethyl fumarate & $0(0)$ & $3(2.3)$ & $3(2.2)$ & \\
\hline Duration of DMT use, $y$, median (IQR) & $13.2(8.0-18.5)$ & $13.0(7.5-16.0)$ & $13.1(7.5-16.1)$ & 0.7779 \\
\hline Reason for stopping DMT, n (\%) & & & & 0.5719 \\
\hline Patient initiated, without physician & $6(75.0)$ & $68(53.1)$ & $74(54.4)$ & \\
\hline Patient initiated, with physician & $2(25.0)$ & $45(35.2)$ & $47(34.6)$ & \\
\hline Physician initiated & $0(0)$ & $15(11.7)$ & $15(11.0)$ & \\
\hline
\end{tabular}

Abbreviations: $\mathrm{DMT}=$ disease-modifying therapy; $\mathrm{IQR}=$ interquartile range.

${ }^{a}$ Ever active vs never active, excluding $\mathrm{n}=4$ with unavailable/indeterminant MRI data.

${ }^{\mathrm{b}}$ Ever vs never spinal cord lesion. 


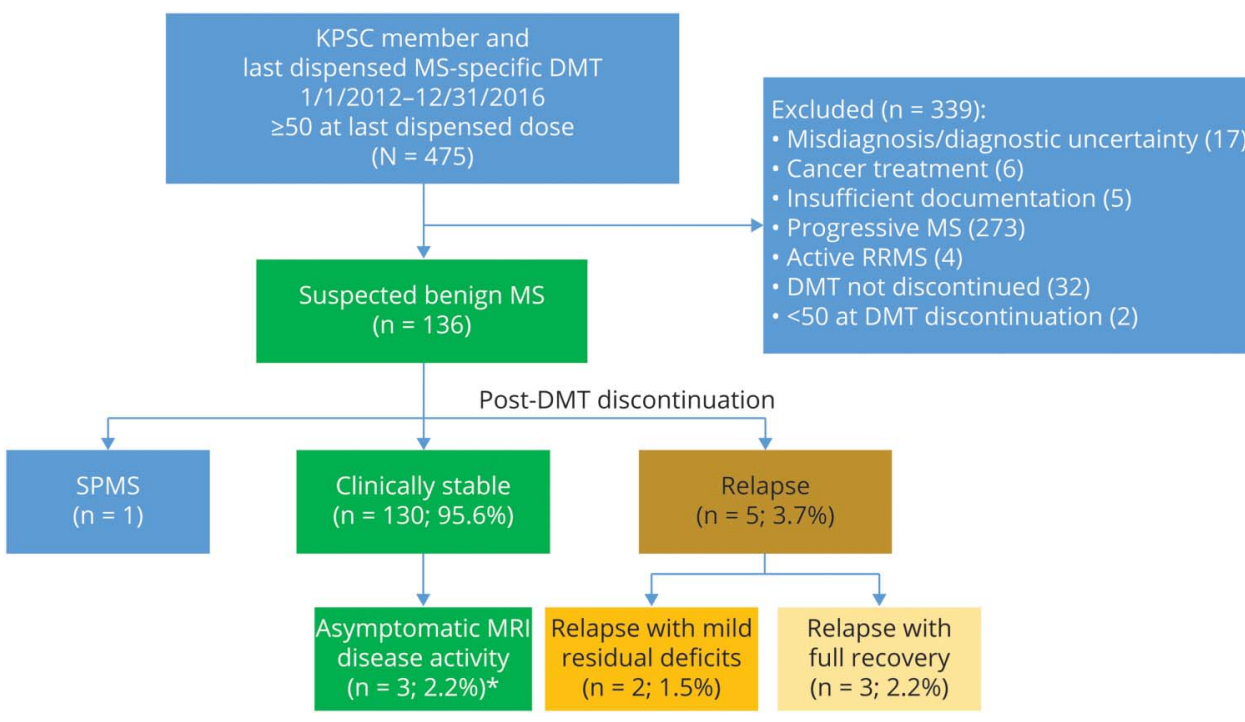

Depicted is the study inclusion flowchart and post-DMT discontinuation outcomes among the patients with MS with a suspected benign/burntout disease course at the time of DMT discontinuation. Of the 475 KPSC members whose last dispensed MS DMT was between 2012 and 2016, and who were 50 years or older at the time of last dispensed DMT, 136 had a suspected benign/burnt-out disease course at DMT discontinuation. Of these, only 5 experienced a relapse following DMT discontinuation, of which only 2 resulted in new, albeit mild, residual deficits. *Asymptomatic MRI disease activity was defined according to the MAGNIMS criteria ${ }^{16}$ to avoid misclassification of microvascular ischemic changes as MS disease activity. DMT = diseasemodifying therapy; $\mathrm{dz}=$ disease; KPSC = Kaiser Permanente Southern California; RRMS = relapsing-remitting MS; SPMS = secondary progressive MS.

of DMT discontinuation (table 1). Two patients had significant residual disability from their MS onset relapse (EDSS = 6.0 and 7.5). Both patients were treated with GLAT ( 1 also with mitoxantrone at disease onset) and had no further relapses or disability progression before or after GLAT discontinuation. Seventy-nine $(58.1 \%)$ patients were diagnosed with MS while KPSC members.

Of interest, 50 (36.8\%) patients had only 1 lifetime MS relapse. These patients were relapse free for a median of 12.5 years (IQR = 8.8-16.2 years), and only 9 (18\%) had new MRI disease activity after diagnosis and before DMT cessation. Following DMT discontinuation, 1 had asymptomatic MRI disease activity, and 1 had a relapse with mild residual sensory symptoms, declined to resume DMTs, and remained relapse free 5 years later.

Most patients ( $\mathrm{n}=112,82.4 \%$ ) had multiple MRIs before DMT discontinuation, over an average of 9.5 years (SD 4.8). Eighty patients $(58.8 \%)$ had never had an active MRI scan recorded during their KP membership; among those who did, the time since last active MRI was similar across groups defined by outcomes (table 1). Following DMT discontinuation, most patients had at least 1 brain MRI scan $(\mathrm{n}=114,83.8 \%)$.

Patients who experienced inflammatory disease activity following DMT discontinuation were younger and had experienced a relapse more recently compared with those who remained relapse and MRI activity free, although the later finding did not reach statistical significance in crude comparisons (table 1). Disease duration, MS-related disability, relapses or active MRI in the past 3 or 5 years, presence of spinal cord lesions, and type of DMT being discontinued were similar across groups defined by outcomes. MRI disease activity was rare and did not differ across groups (table 1).
Of the 5 patients with relapses after DMT discontinuation, 3 (2.2\%) made full recoveries, and 2 (1.5\%) had mild residual deficits (figure 1). One described above with mild residual numbness; another developed bilateral uveitis without any MRI disease activity, refused treatment, and eventually improved with mild residually impaired visual acuity $(20 / 40)$ in 1 eye. One patient reported having SPMS and stopping the DMT because it was not helping, but the general neurologist's notes did not document progressive deficits or symptoms to support transition to SPMS until after DMT discontinuation; thus, the patient was included in the study. This patient developed progressive disability in the absence of relapses or MRI disease activity and remained off DMTs during the follow-up period.

Eight patients (5.9\%) restarted DMTs after a median of 20.2 months after discontinuation (IQR $=8.7-38.8$ ), 5 following disease activity, 2 based on patient/physician preference, and 1 after small vessel disease changes on MRI were mistaken for new MS disease activity. In total, we identified 6 (4.4\%) patients post-DMT discontinuation whose MRI reports misclassified new or slightly enlarged $\mathrm{T} 2$ lesions attributable to small vessel disease/microvascular ischemia or differences in scanning protocols as MS-related demyelinating disease. Assuming that inflammatory disease activity would have been prevented had the patients continued their DMT, the number needed to treat (NNT) to prevent a single relapse with incomplete recovery is 66.7 for 5 years, and to prevent any relapse, 27.0 for 5 years.

\section{Discussion}

Discontinuing DMTs in our population of patients with suspected benign/burnt-out MS appears safe. Only 5 of 136 
patients had a relapse, and none accumulated significant disability following DMT discontinuation. Of interest, approximately one-third of patients had only a single lifetime relapse, and approximately half had spinal cord involvement without clinically significant disability. Younger age in this older population was associated with an increased risk of relapse and/or MRI disease activity after DMT discontinuation. Taken together with previous studies, ${ }^{9-11}$ these findings suggest that for those with 2 or more lifetime relapses, benign/burn-out MS is best reserved for those aged 55 years and older and that MRI evidence of spinal cord involvement does not preclude the possibility of benign/burnt-out MS. Our 2020 consensus case definition for benign/burnt-out MS are presented in table 2 .

Defining benign MS is controversial ${ }^{4,5}$ yet increasingly important. The controversy stems in part from older definitions that combined disease duration of 10 or 15 years with no significant physical disability (EDSS $\leq 2.5$ or 3.0 ) but fail to account for young patients who may meet these definitions at ages 30-35 years, and are still at risk of relapses and transitioning to SPMS. Transition to SPMS is an age-related phenomenon, typically beginning in the $40 \mathrm{~s}$, but often not recognized for several years. ${ }^{23,24}$ For this reason, we do not recommend attempting to classify a person with 2 or more lifetime attacks (i.e., meet Poser criteria) as benign MS before age 55 years. Other objections have been raised over the term benign because it does not capture disabling symptoms like fatigue, depression, or neuropathic pain ${ }^{5}$ and because older definitions do not include MS-related cognitive dysfunction. ${ }^{6}$ For these reasons, we prefer the combined term benign/burntout. We, like others, ${ }^{6}$ consider progressive cognitive decline an indicator of SPMS. The rationale that benign MS is not an MS subtype because it is an RRMS outcome is illogical as SPMS is also an RRMS outcome.

Accurately identifying patients with benign/burnt-out MS has become more urgent to spare these patients the financial toxicity of DMTs ${ }^{25}$ and the unnecessary serious risks of DMTs that are increasingly being prescribed (dimethyl fumarate, teriflunomide, B cell-depleting drugs, natalizumab, and alemtuzumab). The most recent American Academy of Neurology MS treatment guidelines ${ }^{26}$ acknowledge these real-world clinical challenges and recommend considering stopping DMTs in stable MS but do not define this.

Some experts have raised concerns that DMT discontinuation, even in patients with potentially benign/burnt-out MS, will lead to rebound disease activity resulting in irreversible disability. In this respect, findings from our and prior studies ${ }^{9-11}$ are reassuring, with none finding evidence of uncontrolled inflammatory disease activity following discontinuation of DMTs in older patients, regardless of MS subtype. Previous observational studies that have compared patients with MS who continued on DMTs to those who discontinued showed no difference in the risk of relapses. ${ }^{9-11}$ Even with the very generous assumption that continuing DMTs would have
Table 2 KPSC's Proposed Diagnostic Criteria for Benign/ Burnt-Out MS

Must meet all the following criteria

(1) $\geq 55$ y of age

(2) Absence of progressive MS at any time in the disease course

(3) Normal/near-normal neurologic examination (EDSS $\leq 3.0$ )

OR

Stable residual deficits from old relapse ( $\geq 10$ y prior)

(4) No relapse in the past $5 \mathrm{y}^{\mathrm{a}}$

(5) No new/enlarging typical T2 MS lesions ${ }^{\mathrm{b}}$ in the past $5 \mathrm{y}^{\mathrm{a}}$

(6) $\geq 10 y$ of disease duration

Abbreviations: DMT = disease-modifying therapy; EDSS = Expanded Disability Status Scale; KPSC = Kaiser Permanente Southern California.

${ }^{a}$ For patients who meet these criteria while treated with natalizumab, fingolimod, other sphingosine-1-receptor modulators, or other DMTs associated with rebound disease activity, we recommend a single dose of B cell-depleting DMT to prevent rebound disease activity.

b Periventricular, juxtacortical, infratentorial lesions. ${ }^{22}$

prevented all relapses and/or MRI disease activity, the NNT of 27 over 5 years to prevent 1 relapse in this population underscores the low value of continuing DMTs in these patients with benign/burnt-out MS.

It is worth noting that the vast majority of patients were discontinuing DMTs that have not been associated with rebound disease activity. ${ }^{9-11}$ For those patients discontinuing DMTs associated with rebound relapses (e.g., natalizumab and sphingosine-1-receptor modulators), we generally recommend a single dose of a B cell-depleting DMT given the uncertain risks.

We found a slightly higher proportion of postdiscontinuation relapses (3.7\%) compared with a previous study of DMT discontinuation in patients over $60(0.6 \%)^{9}$ and a lower risk of relapse and rate of restarting DMTs compared with the study of DMT discontinuation in patients over the age of 18 (36.4\%), ${ }^{11}$ despite similar lengths of follow-up, yet similarly low rate of restarting DMTs. These differences in post-discontinuation relapses are most likely because we included only patients with suspected benign/burnt-out MS who were on average 60 years old at DMT discontinuation, whereas the other studies included patients with progressive forms of MS (67.4\%), ${ }^{9}$ who were older (mean age 65 years) ${ }^{9}$ or younger (mean age 45 years $)^{11}$ compared with our patients.

Further increasing the sense of urgency to identify patients with benign/burnt-out MS is their expected rise in prevalence with the multiple revisions to the MS diagnostic criteria. ${ }^{13}$ With the incorporation of MRIs in MS diagnostic criteria (a highly sensitive diagnostic test) and revisions to include those with a single relapse, a single second demyelinating lesion on MRI and the presence of oligoclonal bands in the $\operatorname{CSF}^{13}$ are 
expected to lead to an increased incidence of mildly affected cases, a finding supported by the dropping relapse rate in placebo arms of randomized controlled trials ${ }^{27,28}$ and our contemporary, population-based MS cohort. ${ }^{21}$ We also expect that it will lead to overdiagnosis of MS, similar to how screening mammography has led to an overdiagnosis of breast cancer. ${ }^{29}$ Our finding that approximately one-third of patients with benign/burnt-out MS had had only a single lifetime relapse after a total median of 12.5 years of follow-up, yet were exposed to 8-16 years of DMT treatment, supports the concern of MS overdiagnosis and overtreatment. Although these patients only met CIS criteria at diagnosis, by current diagnostic criteria, they have MS.

We therefore think it is reasonable to discuss a trial of DMT discontinuation in patients with a single lifetime relapse after $\geq 10$ years of clinical and radiographic stability, regardless of age. However, a term other than benign/burnt-out MS should be used in younger patients because the pathophysiologic process resulting in disease quiescence is not immunosenescence. At what age and after how many years of lack of disease activity a trial of DMT discontinuation would be safe in younger patients needs to be addressed in future studies.

We were surprised to find that spinal cord lesions on MRI were common in our benign/burnt-out MS cohort, most of whom had no significant disability. At first glance, this seems counterintuitive as spinal cord lesions on MRI are associated with a higher risk of MS-related disability. ${ }^{17}$ However, this may be because MRI evidence of spinal cord lesions alone fails to consider the severity of myelopathic involvement. It has long been recognized that sphincter and motor symptoms (i.e., bad myelopathic relapses) early in MS disease course are strongly associated with an increased risk of conversion to SPMS, but sensory symptoms (including mild myelopathic relapses) have no prognostic significance. ${ }^{14}$ Thus, the presence of spinal cord MRI lesions alone should not be considered an exclusion criterion for suspected benign/burnt-out MS or a trial of DMT discontinuation.

Following DMT discontinuation, 6 patients had new or enlarging T2 lesions from either small vessel disease or differences in scanning protocols that were mistaken as indicators of MS disease activity. This is a real-world challenge in communitybased practices where radiologists' reports are often vague (e.g., slight increase in scattered T2 lesions) and neurologists lack the skills to correctly identify typical MS lesions, ${ }^{30}$ particularly in aging patients with MS and vascular risk factors. Future studies of operational definitions of benign/burnt-out MS should examine requiring unequivocally new typical MS plaques (e.g., periventricular, juxtacortical, or infratentorial lesions) as we did or loosening this requirement in patients older than 65 years who have been clinically stable for many years.

The main limitations of this study are selection bias and lack of a comparator group. As such, our findings should not be extrapolated to younger patients, those with relapses and/or MRI disease activity within the past 3 years or those with relatively short disease duration as we had very few of these patients in our cohort, and it is possible that many of these patients remained on DMTs. We also found relatively few patients younger than 55 years who met the inclusion criteria. We may have underestimated how many elderlies with MS remain stable off DMTs, as we did not include those who never took DMTs or stopped them before age 50 years. Other limitations include small sample size and reliance on routine medical records. This resulted in misclassification of 1 patient with early SPMS as potentially benign and may have resulted in inaccurate estimates of MRI disease activity due to irregular scanning intervals and lack of standardized acquisition protocols. Strengths of our study include the importance of the question and access to patients' complete medical records including all interactions with non-neurology health care providers.

Taken together with population-based natural history studies $^{2,3}$ and findings from previous DMT discontinuation studies, stopping DMTs in older patients following a prolonged period of disease inactivity appears safe. Operational definitions that can accurately identify patients with benign/ burnt-out MS in regular practice settings are needed. Although this study provides a reasonable starting point, future studies to identify precise cutoffs for chronological age and time since last relapse or last active MRI are needed.

\section{Acknowledgment}

We thank the KPSC MS Specialist Group (Brandon E. Beaber, MD, Downey Medical Center, Department of Neurology, Southern California Permanente Medical Group; Sonu M Brara, MD, Panorama City Medical Center, Department of Neurology, Southern California Permanente Medical Group; Julie Debacker, MD, Los Angeles Medical Center, Department of Neurology, Southern California Permanente Medical Group; and Oluwasheyi Ayeni, MD, Glenlake Medical Center, Department of Neurology, Southeast Permanente Medical Group) for helpful feedback and development of the consensus definition for benign/burnt-out MS.

\section{Study Funding}

No targeted funding reported.

\section{Disclosure}

A. Langer-Gould has received grant support and awards from the NIH, Patient-Centered Outcomes Research Institute, and the National MS Society; she currently serves as a voting member on the California Technology Assessment Forum, a core program of the Institute for Clinical and Economic Review (ICER); and she has received sponsored and reimbursed travel from ICER. D. McFaul, N.N. Hakopian, J.B. Smith, and A.S. Nielsen report no disclosures. Go to Neurology.org/NN for full disclosures.

\section{Publication History}

Received by Neurology: Neuroimmunology \& Neuroinflammation July 23, 2020. Accepted in final form December 14, 2020. 
Appendix Authors

\begin{tabular}{|c|c|c|}
\hline Name & Location & Contribution \\
\hline $\begin{array}{l}\text { Derek } \\
\text { McFaul, DO }\end{array}$ & $\begin{array}{l}\text { Los Angeles Medical Center, } \\
\text { Department of Neurology, } \\
\text { Southern California } \\
\text { Permanente Medical Group }\end{array}$ & $\begin{array}{l}\text { Collected the data and } \\
\text { revised the manuscript for } \\
\text { content }\end{array}$ \\
\hline $\begin{array}{l}\text { Nektar N. } \\
\text { Hakopian, } \\
\text { PharmD }\end{array}$ & $\begin{array}{l}\text { Los Angeles Medical Center, } \\
\text { Department of Drug Use } \\
\text { Management, Kaiser } \\
\text { Permanente }\end{array}$ & $\begin{array}{l}\text { Collected the data and } \\
\text { revised the manuscript for } \\
\text { content }\end{array}$ \\
\hline $\begin{array}{l}\text { Jessica B. } \\
\text { Smith, MPH }\end{array}$ & $\begin{array}{l}\text { Department of Research \& } \\
\text { Evaluation, Southern } \\
\text { California Permanente } \\
\text { Medical Group, Pasadena }\end{array}$ & $\begin{array}{l}\text { Collected, analyzed, and } \\
\text { interpreted the data and } \\
\text { revised the manuscript for } \\
\text { content }\end{array}$ \\
\hline $\begin{array}{l}\text { Allen Scott } \\
\text { Nielsen, MD }\end{array}$ & $\begin{array}{l}\text { Fontana Medical Center, } \\
\text { Department of Neurology, } \\
\text { Southern California } \\
\text { Permanente Medical Group, } \\
\text { Fontana }\end{array}$ & $\begin{array}{l}\text { Interpreted the data and } \\
\text { revised the manuscript for } \\
\text { content }\end{array}$ \\
\hline $\begin{array}{l}\text { Annette } \\
\text { Langer- } \\
\text { Gould, MD, } \\
\text { PhD }\end{array}$ & $\begin{array}{l}\text { Los Angeles Medical Center, } \\
\text { Department of Neurology, } \\
\text { Southern California } \\
\text { Permanente Medical Group }\end{array}$ & $\begin{array}{l}\text { Designed and } \\
\text { conceptualized the study; } \\
\text { collected, analyzed, and } \\
\text { interpreted the data; } \\
\text { drafted and revised the } \\
\text { manuscript for intellectual } \\
\text { content; had full access to } \\
\text { all the data, and takes } \\
\text { responsibility for the } \\
\text { integrity of the data and } \\
\text { accuracy of the data } \\
\text { analysis }\end{array}$ \\
\hline
\end{tabular}

\section{References}

1. Fulop T, Larbi A, Dupuis G, et al. Immunosenescence and inflamm-aging as two sides of the same coin: friends or foes? Front Immunol 2017;8:1960.

2. Pittock SJ, McClelland RL, Mayr WT, et al. Clinical implications of benign multiple sclerosis: a 20-year population-based follow-up study. Ann Neurol 2004;56:303-306.

3. Eriksson M, Andersen O, Runmarker B. Long-term follow up of patients with clinically isolated syndromes, relapsing-remitting and secondary progressive multiple sclerosis. Mult Scler 2003;9:260-274.

4. Lublin FD, Reingold SC, Cohen JA, et al. Defining the clinical course of multiple sclerosis: the 2013 revisions. Neurology 2014;83:278-286.

5. Tallantyre EC, Major PC, Atherton MJ, et al. How common is truly benign MS in a UK population? J Neurol Neurosurg Psychiatry 2019;90:522-528.

6. Reynders T, D’Haeseleer M, De Keyser J, Nagels G, D’Hooghe MB. Definition, prevalence and predictive factors of benign multiple sclerosis. eNeurologicalSci 2017;7:37-43.

7. Institute for Clinical and Economic Review (ICER). Disease-Modifying Therapies for Relapsing-Remitting and Primary-Progressive Multiple Sclerosis: Effectiveness and Value. Final Evidence Report. Boston: ICER; 2017. Available at: icer-review.org/wpcontent/uploads/2016/08/CTAF_MS_Final_Report_030617.pdf. Accessed September $1,2020$.
8. Butler M, Forte ML, Schwehr N, Carpenter A, Kane RL. Decisional Dilemmas in Discontinuing Prolonged Disease-Modifying Treatment for Multiple Sclerosis. Rockville: Agency for Healthcare Research and Quality (US); 2015.

9. Hua LH, Fan TH, Conway D, Thompson N, Kinzy TG. Discontinuation of diseasemodifying therapy in patients with multiple sclerosis over age 60. Mult Scler 2019;25: 699-708.

10. Yano H, Gonzalez C, Healy BC, Glanz BI, Weiner HL, Chitnis T. Discontinuation of disease-modifying therapy for patients with relapsing-remitting multiple sclerosis: effect on clinical and MRI outcomes. Mult Scler Relat Disord 2019;35:119-127.

11. Kister I, Spelman T, Alroughani R, et al. Discontinuing disease-modifying therapy in MS after a prolonged relapse-free period: a propensity score-matched study. J Neurol Neurosurg Psychiatry 2016;87:1133-1137.

12. Langer-Gould AM, Anderson WE, Armstrong MJ, et al. The American Academy of Neurology's top five choosing wisely recommendations. Neurology 2013;81: 1004-1011.

13. Thompson AJ, Banwell BL, Barkhof F, et al. Diagnosis of multiple sclerosis: 2017 revisions of the McDonald criteria. Lancet Neurol 2018;17:162-173.

14. Swanton JK, Fernando KT, Dalton CM, et al. Early MRI in optic neuritis: the risk for disability. Neurology 2009;72:542-550.

15. Sombekke MH, Wattjes MP, Balk LJ, et al. Spinal cord lesions in patients with clinically isolated syndrome: a powerful tool in diagnosis and prognosis. Neurology 2013;80:69-75.

16. Arrambide G, Rovira A, Sastre-Garriga J, et al. Spinal cord lesions: a modest contributor to diagnosis in clinically isolated syndromes but a relevant prognostic factor. Mult Scler 2018;24:301-312.

17. Poser CM, Paty DW, Scheinberg L, et al. New diagnostic criteria for multiple sclerosis: guidelines for research protocols. Ann Neurol 1983;13:227-231.

18. Langer-Gould A, Popat RA, Huang SM, et al. Clinical and demographic predictors of long-term disability in patients with relapsing-remitting multiple sclerosis: a systematic review. Arch Neurol 2006;63:1686-1691.

19. Bhatia R, Singh N. Can we treat secondary progressive multiple sclerosis now? Ann Indian Acad Neurol 2019;22:131-136.

20. Koebnick C, Langer-Gould AM, Gould MK, et al. Sociodemographic characteristics of members of a large, integrated health care system: comparison with US Census Bureau data. Perm J 2012;16:37-41.

21. Langer-Gould A, Smith JB, Albers KB, et al. Pregnancy-related relapses and breastfeeding in a contemporary multiple sclerosis cohort. Neurology 2020;94: e1939-e1949.

22. Filippi M, Rocca MA, Ciccarelli O, et al. MRI criteria for the diagnosis of multiple sclerosis: MAGNIMS consensus guidelines. Lancet Neurol 2016;15:292-303.

23. Tutuncu M, Tang J, Zeid NA, et al. Onset of progressive phase is an age-dependent clinical milestone in multiple sclerosis. Mult Scler 2013;19:188-198.

24. Katz Sand I, Krieger S, Farrell C, Miller AE. Diagnostic uncertainty during the tran sition to secondary progressive multiple sclerosis. Mult Scler 2014;20:1654-1657.

25. San-Juan-Rodriguez A, Good CB, Heyman RA, Parekh N, Shrank WH, Hernandez I Trends in prices, market share, and spending on self-administered disease-modifying therapies for multiple sclerosis in Medicare Part D. JAMA Neurol 2019;76: $1386-1390$

26. Rae-Grant A, Day GS, Marrie RA, et al. Practice guideline recommendations summary: disease-modifying therapies for adults with multiple sclerosis: report of the Guideline Development, Dissemination, and Implementation Subcommittee of the American Academy of neurology. Neurology 2018;90:777-788.

27. Johnson KP, Brooks BR, Cohen JA, et al. Copolymer 1 reduces relapse rate and improves disability in relapsing-remitting multiple sclerosis: results of a phase III multicenter, double-blind placebo-controlled trial. The Copolymer 1 Multiple Sclerosis Study Group. Neurology 1995;45:1268-1276.

28. Gold R, Kappos L, Arnold DL, et al. Placebo-controlled phase 3 study of oral BG-12 for relapsing multiple sclerosis. N Engl J Med 2012;367:1098-1107.

29. Bleyer A, Welch HG. Effect of three decades of screening mammography on breastcancer incidence. N Engl J Med 2012;367:1998-2005.

30. Solomon AJ, Bourdette DN, Cross AH, et al. The contemporary spectrum of multiple sclerosis misdiagnosis: a multicenter study. Neurology 2016;87:1393-1399. 


\section{Neurology \\ Neuroimmunology \& Neuroinflammation}

\section{Defining Benign/Burnt-Out MS and Discontinuing Disease-Modifying Therapies}

Derek McFaul, Nektar N. Hakopian, Jessica B. Smith, et al.

Neurol Neuroimmunol Neuroinflamm 2021;8;

DOI 10.1212/NXI.0000000000000960

This information is current as of February 8, 2021

\section{Updated Information \& Services}

References

Subspecialty Collections

Permissions \& Licensing

Reprints including high resolution figures, can be found at: http://nn.neurology.org/content/8/2/e960.full.html

This article cites 28 articles, 2 of which you can access for free at: http://nn.neurology.org/content/8/2/e960.full.html\#\#ref-list-1

This article, along with others on similar topics, appears in the following collection(s):

Autoimmune diseases

http://nn.neurology.org//cgi/collection/autoimmune_diseases

Cohort studies

http://nn.neurology.org//cgi/collection/cohort_studies

Multiple sclerosis

http://nn.neurology.org//cgi/collection/multiple_sclerosis

Information about reproducing this article in parts (figures,tables) or in its entirety can be found online at:

http://nn.neurology.org/misc/about.xhtml\#permissions

Information about ordering reprints can be found online:

http://nn.neurology.org/misc/addir.xhtml\#reprintsus

Neurol Neuroimmunol Neuroinflamm is an official journal of the American Academy of Neurology.

Published since April 2014, it is an open-access, online-only, continuous publication journal. Copyright

Copyright $\odot 2021$ The Author(s). Published by Wolters Kluwer Health, Inc. on behalf of the American

Academy of Neurology.. All rights reserved. Online ISSN: 2332-7812.

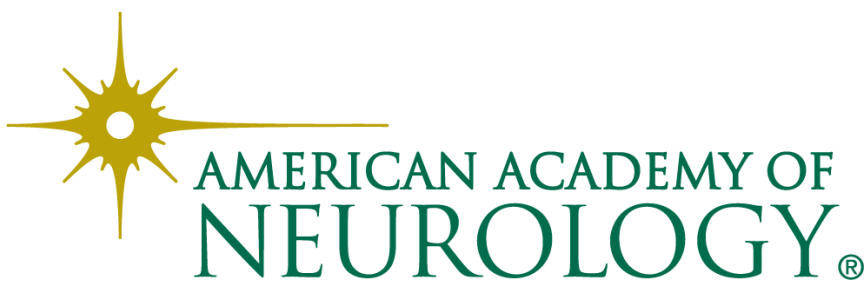

